\title{
Low dose aspirin lowered stroke risk but not risk of myocardial infarction or cardiovascular death in women
}

Ridker PM, Cook NR, Lee I-M, et al. A randomized trial of low-dose aspirin in the primary prevention of cardiovascular disease in women. N Engl J Med 2005;352:1293-304.

\section{Q Is low dose aspirin effective for primary prevention of cardiovascular disease in women?}

\section{METHODS}

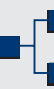

Design: randomised, placebo controlled trial (Women's Health Study).

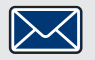

Allocation: $\{$ concealed\}.*

Blinding: blinded \{healthcare providers, participants, data collectors, and outcome assessors\}.*

Follow up period: mean 10 years.

Setting: United States and Puerto Rico.

की

Patients: 39876 women $\geqslant 45$ years of age (mean age $55 \mathrm{y}$ ) who had no history of coronary heart disease, cerebrovascular disease, cancer (except non-melanoma skin cancer), or other major chronic illness; had no history of side effects to study medications; were not using aspirin or non-steroidal antiinflammatory medications; were not taking anticoagulants or corticosteroids; and were not taking vitamin $A$ or $E$, or $\beta$ carotene supplements more than once per week.

$\mathbf{R}_{\mathbf{X}}$

Intervention: aspirin, $100 \mathrm{mg}$ every other day ( $\mathrm{n}=19$ 934), or placebo $(n=19942)$

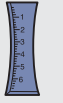

Outcomes: first major cardiovascular event (non-fatal myocardial infarction, non-fatal stroke, or death from cardiovascular causes); individual cardiovascular endpoints; and adverse events.

IDCrticipant follow up: $97 \%$ (intention to treat analysis).

*Information provided by author

For correspondence: Dr JE Buring Brigham and Women's Hospital, Boston, MA, USA. jburing@rics.bwh.harvard.edu

Sources of funding: National Heart, Lung, and Blood Institute and National Cancer Institute. Aspirin and placebo provided by Bayer Health Care; vitamin E and placebo provided by Natural Source Vitamin E Association.

\section{MAIN RESULTS}

Women receiving aspirin and those receiving placebo did not differ for rates of a first major cardiovascular event, death from cardiovascular causes, or fatal or non-fatal myocardial infarction (table). Women receiving aspirin had lower rates of stroke and transient ischemic attack but a higher rate of gastrointestinal bleeding requiring transfusion than those receiving placebo (table).

\section{CONCLUSION}

Low dose aspirin lowered risk of stroke in women but not risk of myocardial infarction or death from cardiovascular causes.

\section{A modified version of this abstract appears in ACP Journal Club.}

\section{Commentary}

The landmark 10 year study by Ridker et al of nearly 40000 initially healthy women found that taking prophylactic low dose $(100 \mathrm{mg})$ aspirin every other day did not confer the same benefits to women as it did to men. Few therapies have separately analysed effects by sex, and the findings lead us to ponder why many of the therapies used for women are not effective or are even harmful. The authors note that the reasons for any sex based differences in the efficacy of aspirin for primary prevention of cardiovascular disease are unclear and require further exploration.

The strengths of the study were that it had a large sample size; was double blinded, randomised, and placebo controlled; and used a single simple intervention and clear outcomes. The treatment and control groups were well balanced in terms of initial characteristics, and follow up for outcome measurement was excellent. The study also considered both risks and benefits. An interesting finding from subgroup analyses was that the women (10\% of the study population) who seemed to benefit most were those $\geqslant 65$ years of age. In this group, aspirin use led to 44 fewer myocardial infarctions, strokes, or deaths from cardiovascular causes but also to 16 more gastrointestinal haemorrhages requiring transfusion.

The women in the study were generally at low risk for cardiovascular events, and $<3 \%$ of women in the placebo group had a major cardiovascular event during the 10 year follow up period. Based on the fact that aspirin was more effective in older women and that cardiovascular risk increases with age, it seems sensible to advocate use of low dose aspirin in this group. It is less clear whether aspirin should be used in younger women unless they have high global risk scores. This study offers women additional valuable evidence to help inform their choices about aspirin for primary prevention of cardiovascular disease. David R Thompson, RN, PhD, MBA, FRCN, FESC Chinese University of Hong Kong Hong Kong, People's Republic of China

Aspirin $v$ placebo for primary prevention of cardiovascular disease in women*

\begin{tabular}{|c|c|c|c|c|}
\hline Outcomes at mean 10 years & Aspirin & Placebo & $\operatorname{RRR}(95 \% \mathrm{Cl})$ & NNT (Cl) \\
\hline $\begin{array}{l}\text { Major cardiovascular event† } \\
\text { Stroke } \\
\text { Death from cardiovascular causes } \\
\text { Transient ischemic attack }\end{array}$ & $\begin{array}{l}2.4 \% \\
1.1 \% \\
0.60 \% \\
0.93 \%\end{array}$ & $\begin{array}{l}2.6 \% \\
1.3 \% \\
0.63 \% \\
1.2 \%\end{array}$ & $\begin{array}{l}9 \%(-3 \text { to } 20) \\
17 \%(1 \text { to } 31) \\
5 \%(-22 \text { to } 26) \\
22 \%(6 \text { to } 36)\end{array}$ & $\begin{array}{l}\text { Not significant } \\
445 \text { ( } 227 \text { to } 10377) \\
\text { Not significant } \\
385 \text { ( } 216 \text { to } 1687 \text { ) }\end{array}$ \\
\hline & & & RRI (CI) & NNH \\
\hline $\begin{array}{l}\text { Fatal or non-fatal myocardial infarction } \\
\text { Gastrointestinal bleeding requiring transfusion }\end{array}$ & $\begin{array}{l}0.99 \% \\
0.6 \%\end{array}$ & $\begin{array}{l}0.97 \% \\
0.5 \%\end{array}$ & $\begin{array}{l}2 \%(-16 \text { to } 25) \\
40 \% \text { (7 to } 83)\end{array}$ & $\begin{array}{l}\text { Not significant } \\
554 \text { (305 to 2751) }\end{array}$ \\
\hline
\end{tabular}

*Abbreviations defined in glossary; RRR, RRI, NNT, NNH, and $\mathrm{Cl}$ calculated from data in article.

†Major cardiovascular event = non-fatal myocardial infarction, non-fatal stroke, or death from cardiovascular causes. 